\title{
PENCAMPURAN BUDAYA CINA, JAWA, DAN BELANDA PADA BUDAYA MAKAN CINA PERANAKAN
}

\author{
Devanny Gumulya \\ Program Studi Desain Produk, Universitas Pelita Harapan Tangerang \\ devanny.gumulya@uph.edu
}

\begin{abstract}
Abstrak
Budaya Cina peranakan merupakan hasil dari proses akulturasi beberapa budaya. Oleh karena itu, budaya ini sangat menarik untuk dikaji. Paper ini mencoba mengkaji dengan metode studi literatur latar belakang sejarah dan keunikan budaya cina peranakan pada budaya makan mulai dari etiket, menu dan peralatan makan. Dari hasil studi ditemukan bahwa walaupun Cina Peranakan terbentuk dari proses akulturasi budaya Jawa, Cina dan Belanda tetapi dalam hal budaya makan, budaya Cina masih mendominasi terutama dalam etiket dan peralatan makan, karena bagi orang Cina makan dipandang sebagai pemersatu keluarga. Akulturasi terjadi pada menu makanan ada unsur bercampur dengan bahan yang tersedia di Indonesia, hal ini terjadi pada lumpia Semarang yang terkenal dengan lumpia berisi rebung sesuai dengan bahan yang tersedia di Semarang.
\end{abstract}

Kata kunci : Akulturasi Budaya, Cina Peranakan, Budaya makan

\begin{abstract}
Cina Peranakan culture is a result of acculturation from different cultures. Therefore, this culture is so interesting to be researched. With literature study method, this paper tries to elaborate the historic point of view to gain closer understanding and synthesize the culture uniqueness with eating culture as object study case. From the study founded that although Cina Peranakan is the melting pot between Java, Dutch and Chinese Cultures, but in food culture the Chinese culture still dominates specially in eating etiquette and tableware. This because for Chinese food is believed as means for family gathering. Meanwhile, the acculturation can be seen in the food menu, because the ingredients needs to be adapted with resources available in Indonesia, this can be seen in Semarang Lumpia that is reknown for rebung, the vegetable available there.
\end{abstract}

Keywords : Culture assimilation, Cina Peranakan culture, Eating culture

\section{PENDAHULUAN}

Menurut Gondomo, Ph.D. (Kwa dkk., 2009); kebudayaan adalah segala sesuatu yang diteruskan atau diwariskan dari satu orang kepada orang lain sebagai anggota masyarkat, dengan cara belajar, disuruh (atau tidak disuruh) menirukan, diberi contoh atau teladan, tetapi bukan Sesutu yang diteruskan dan diwariskan secara genetik. Oleh sebab itu, semua ciri fisik seperti warna kulit, bentuk mata, hidung, dan lainnya yang diperoleh dari ayah dan ibu bukannlah suatu kebudayaan. Nilai-nilai kebudayaan dapat diperoleh dengan cara memperhatikan atau meniru penggunaan bahasa, cara dan selera makan, cara memasak, cara duduk, sopan santun, tutur kata, tata nilai, keyakinan religious, pandangan hidup, keterampilan, kebiasaan, dari orang tua, keluarga, teman, guru, pemimpin, raja dan sebagainya. 
Sepanjang sejarah, Indonesia dikenal sebagai negara maritim yang multikultur akibat hubungan dagang antar bangsa seperti Eropa, Cina, Arab dan lainnya. Hal ini mendorong Indonesia untuk mengembangkan budayanya sendiri dengan pengaruh pengaruh budaya lainnya. Salah satu budaya yang mempengaruhi Indonesia dan adalah budaya Cina berasimiliasi dengan budaya lokal dan disebut dengan Budaya Cina Peranakan.

Asal mula berawal dari hubungan dagang antara Indonesia dengan Cina terbentuk sejak berabad-abad yang lalu. Melalui hubungan dagang, banyak orang-orang Cina kemudian menetap dan memiliki keturunan dari perempuan setempat yang lahir di beberapa bagian Indonesia dan disebut sebagai Cina peranakan. Selain mengandung budaya Cina dan Indonesia, budaya Cina peranakan juga mendapat pengaruh dari budaya barat, khususnya Belanda. Masa penjajahan Belanda yang berlangsung cukup lama di Indonesia mengakibatkan terserapnya budaya negara tersebut masuk ke dalam pola hidup masyarakat di saat itu. Interaksi masyarakat dari ketiga negara yang berbeda tersebutlah yang menjadi faktor utama terciptanya keindahan budaya Cina peranakan. Dapat disimpulkan bahwa budaya Cina peranakan merupakan silang budaya antara budaya Indonesia (mayoritas Jawa), budaya barat (mayoritas Belanda), dan budaya Cina.

\section{METODE PENELITIAN}

Permasalahan yang dijawab di paper ini menggunakan metode studi literatur dengan pendekatan kualitatif adalah

a. Latar belakang sejarah budaya Cina Peranakan.

b. Analisa budaya makan Cina Peranakan sebagai studi asimilasi budaya Cina, Jawa dan Belanda.

c. Identifikasi aspek apa pada budaya makan yang mengalami asimilasi budaya paling banyak .

Budaya makan Cina Peranakan akan dikaji dalam teori tiga level budaya (Ling et al., 2007)

1. Level luar mencakup semua budaya yang dapat disentuh secara fisik seperti makanan, kain , arsitektur, alat transportasi, dan lain-lain.

2. Level tengah adalah perilaku seperti aturan tata krama, norma dan nilai yang mengatur masyarakat dan organisasi.

3. Level dalam adalah level spiritual dan ideologi seperti agama, filosofi dan seni.

\section{PEMBAHASAN}

\subsection{Budaya Cina Peranakan}

Kaum Cina peranakan sebagian besar merupakan campuran dari kaum migran Hokkian dari provinsi selatan di Cina dengan perempuan setempat. Pengaruh pihak perempuan dalam rumah tangga campuran ini melahirkan suatu budaya yang unik dan khas yang diturunkan dari generasi ke generasi, hingga pada saat terbentuknya komunias peranakan di Jawa yang solid dan signifikan (Kwa dkk., 2009). Dalam kehidupan seharihari, kebudayaan golongan ini merupakan campuran dari tiga unsur yaitu Jawa, Cina, 
dan Belanda-walaupun ada juga sebagian kecil peranakan yang terpengaruh budaya di luar pulau Jawa.

Kaum Cina peranakan (yang laki-laki disebut baba, yang perempuan disebut nyonya) merupakan keturunan dari pernikahan laki-laki Cina totok (sinkheh, diambil dari bahasa hokian yang berarti tamu baru) dengan perempuan lokal (nyai). Hingga akhir abad ke-19 masih jarang dijumpai perempuan Cina totok datang ke Indonesia, karena sulitnya pelayaran dan adat-istiadat negeri Cina (Tiongkok) ketika itu (Kwa dkk., 2009 :134). Menurut Datin Seri Endon Mahmood (2004), kata baba (babah) digunakan sebagai panggilan kepada laki-laki terhormat yang awalnya adalah bahasa Persia yang terpengaruh budaya Hindustan, sedangkan nyonya (atau disebut juga sebagai nyonyah, nonya dan nona) datang dari perkataan Indonesia yang berarti wanita yang menikah dengan orang asing.

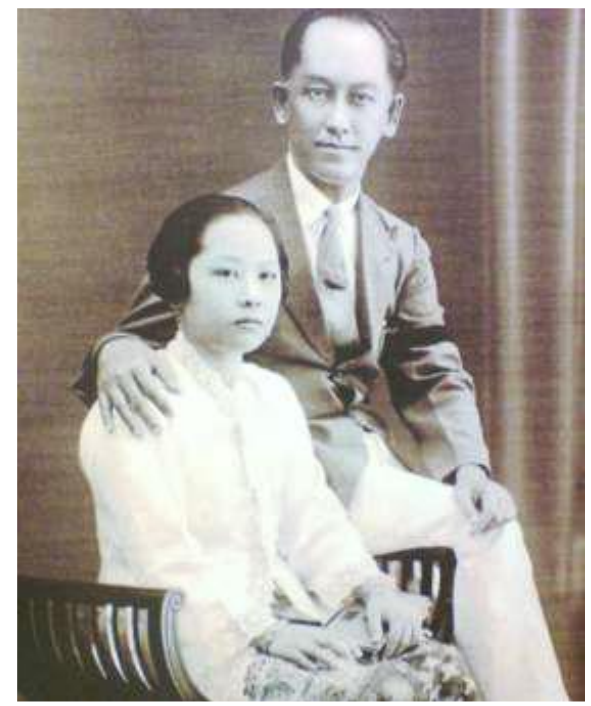

Gambar 1. Sepasang Baba dan Nyonya (Sumber: Mahmood, 2004: 27)

Pada abad ke 17 hingga abad ke 18, orang-orang keturunan Cina yang beragama islam dan memakai nama Bumiputra disebut sebagai peranakan. Istilah itu sekarang hanya dipergunakan untuk menyebut orang Cina yang turun-temurun yang lahir di Indonesia (Ham, 2005: 20). Seorang sejarawan yang bekerja di Arsip National RI, memiliki pendapat yang serupa. Dokumen awal ke-19 menyebut adanya satu jabatan kepala komunitas Tionghoa-Muslim di Batavia yang disebut sebagai "Kapitein der ParnakkanChineezen". Hanya jabatan tersebut dihapus oleh pemerintah kolonial (tahun 1832) dengan alasan warga Tionghoa-Muslim sudah berbaur terserap ke dalam komunitas pribumi di Batavia. Sejak itu istilah "peranakan" bergeser artinya. Cina peranakan yang dimaksud bukan hanya peranakan dalam arti biologis, tetapi juga dalam arti kebudayaan. Kebanyakan dari mereka sudah tidak menggunakan bahasa Cina, melainkan bahasa Melayu, Indonesia, Jawa dan Sunda. Adat-istiadat juga tidak $100 \%$ Cina, tetapi mereka telah mengambil adat-istiadat penduduk pribumi setempat. Dalam perkawinan, kaum Tionghoa peranakan berbeda dengan orang-orang totok yang patrilokaal. Seperti penduduk setempat, kaum peranakan memiliki kebiasaan- 
kebiasaan matrilokaal. Di Surabaya, kedua pengantin Tionghoa peranakan, sesudah menikah beberapa hari lamanya, diharuskan tinggal di rumah orang tua pihak perempuan. Suatu hal yang tak mungkin terjadi di Cina. Dengan demikian kita dapat melihat pencampuran budaya antara Tionghoa peranakan dengan penduduk setempat. Kebudayaan Cina peranakan juga mempunyai aroma Jawa. Mereka suka pada gamelan jawa; banyak di antara kalangan Tionghoa peranakan yang dapat menarikan berbagai tarian jawa.(Ham, 2005: 35-36).

Menurut Winarni (2009), Proses asimilasi atau pembauran kultural menghasilkan orang-orang Cina peranakan yang hidup seperti orang Jawa. Namun keharmonisan hubungan tersebut tidak berlangsung lama, karena banyak garis pemisah baik dari kelompok-kelompok masyarakat Jawa. Bahkan timbul sikap atau perilaku anti-Cina serta kecurigaan yang bersumber dari pengalaman yang mereka temukan selama bertahun-tahun terutama ketika orang-orang Cina semakin hari, di dalam jiwa dan pikiran orang Jawa semakin erat berhubungan dengan kebijaksanaan perekonomian yang dijalankan pemerintah Eropa yang menindas. Di pihak lain, orientasi orang-orang Cina pun berubah sejak warga elit yang menguasai puncak tangga kelas sosial bukan lagi para penguasa pribumi. Keadaan sosial dan politik inilah yang mempunyai pengaruh besar golongan Cina peranakan tidak dapat dilebur dan menjadi sebuah minoritas baru yang sering disebut sebagai golongan "minoritas perantara" (middlemen minority).

Westernisasi jelas terlihat pada kehidupan kaum Cina Peranakan pada abad ke-19 (lihat Gambar 2). Masyarakat pada zaman itu, dan juga mungkin sekarang, melihat ke atas, yakni ke golongan yang lebih tinggi. Westernisasi awalnya hanya terbatas pada kaum elite Tionghoa peranakan. Di Semarang, opsiropsir yang memiliki silsilah panjang di Jawa adalah yang pertama kali mengajukan rekest (surat permohonan) pada pemerintah Belanda untuk memotong kuncir dan berpakaian Belanda. Setelah rekest tersebut diluluskan, Anak-anak Tionghoa peranakan yang pergi ke sekolah Belanda juga diharuskan memotong kuncir mereka dan berpakaian secara barat (Ham, 2005).

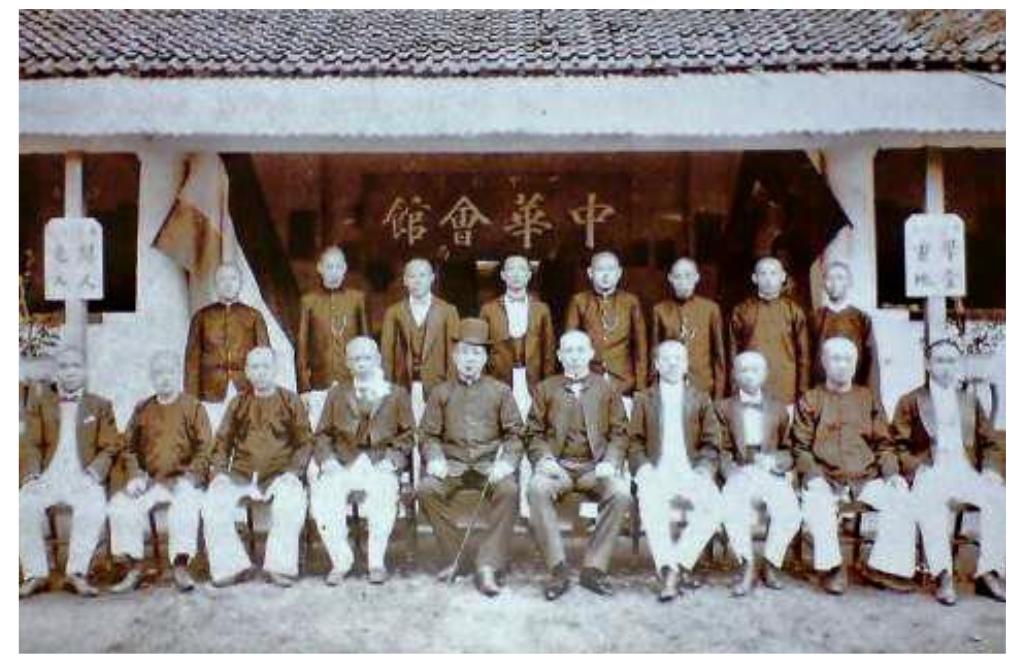

Gambar 2. Sekolah Belanda untuk Anak-anak Tionghoa (Sumber: Kwa dkk., 2009: 37) 
Bisa disimpulkan bahwa Cina peranakan memiliki identitas jamak. Menurut Kwartanada dan Noor (2006), hal tersebut terjadi bukan karena kaum Cina peranakan tidak memiliki satu identitas tunggal dan ada dalam krisis (sering menjadi kambing hitam), namun dikarenakan identitas jamak adalah satu pilihan yang sehat. Oi Hong Kian, seorang peranakan keturunan Kapitan Cina Tan Jin Sing, meneguhkan pernyataan-pernyataan diatas dalam otobiografinya. Dengan bangga dia memandang dirinya sebagai produk "three in one" dan menikmati kemudahan dari identitas jamaknya tersebut, berikut pernyataannya:

\begin{abstract}
"Budaya Cina, Indonesia-Jawa dan Belanda selanjutnya akan menentukan kehidupan saya secara keseluruhan. Ketiga kutub itu berperan penting dalam menentukan cara berpikir dan bertindak. Sublimasi cara berpikir Cina, Jawa dan Belanda menghasilkan kualitas lahiriah dan jasmaniah yang membuat saya menjadi seorang peranakan. Campuran unik, Cina, Jawa dan budaya Belanda telah membentuk saya seperti sekarang. Cina dan Jawa ada dalam darah saya, sementara Belanda terserap dari luar. Campuran tiga dunia itu menyebabkan reaksi kimia yang menghasilkan manusia yang sangat kompleks. Namun, saya tidak merasa demikian. Saya justru merasa itu suatu keuntungan, karena sebagai seorang yang three in one [sic!], dengan mudah saya bisa menghayati dunia yang sama sekali berlainan." (Kwartanada dan Noor, 2006)
\end{abstract}

\title{
3.2. Budaya Makan Cina
}

Budaya makan adalah sistem nilai dan perilaku yang terpola dalam kegiatan makan oleh suatu masyarakat tertentu. Sistem nilai dan perilaku terpola ini sangat mempengaruhi konsep, etiket, dan tata cara makan, mencakup tata ruang makan dan peralatan makannya (Sandika, 2007). Pembahasan budaya makan Cina akan dibagi menurut beberapa kategori di bawah ini. Pembagian budaya makan Cina Peranakan berdasarkan teori tiga level budaya leong et al (2007);

\subsubsection{Level luar (elemen fisik: motif, peralatan makan, menu dan resep, tata letak dapur)}

\section{Perangkat makan Cina}

Untuk mengetahui bentuk dasar piranti makan dan minum, ada beberapa indikator, yaitu: jenis makanan yang diwadahinya, cara pemakaiannya, relasinya dengan piranti lain dan relasinya dengan pemakai. Setiap piranti berfungsi sesuai bentuk dan jenis makanannya. Berikut adalah peralatan makan Cina serta pembahasannya:

\section{a) Mangkuk nasi dan sup}

Bentuk mangkuk menyerupai bentuk dua tangan yang mengadah ke atas seperti lambang bekal biksu untuk mendapatkan sedekah yang menyimbolkan ketidakterikatannya terhadap materi dunia. Bentuk permukaan atas mangkuk nasi harus memudahkan pengambilan nasi ketika digunakan. Dimensinya berbeda-beda tergantung dengan masyarakat pengguna dan daerahnya masing-masing. 
Cara menggunakan mangkuk adalah memegang dengan tangan kiri, karena tangan kanan digunakan untuk memegang sumpit atau sendok (lihat gambar 3 ).

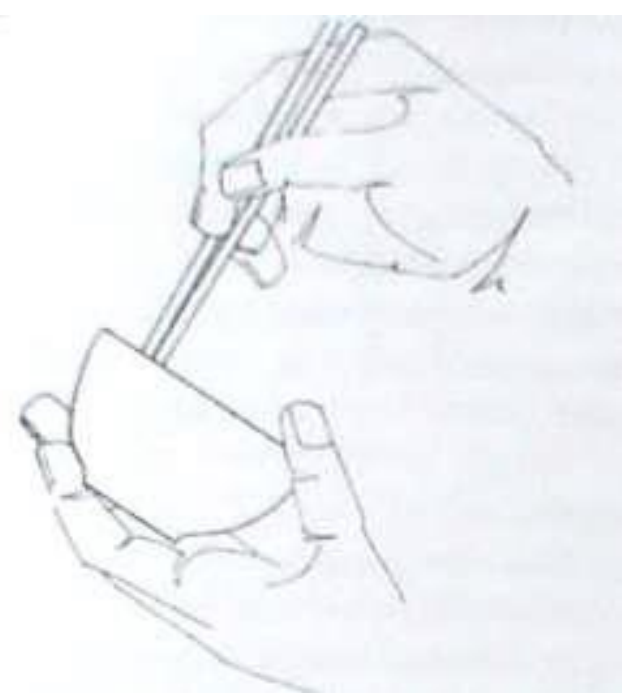

Gambar 3. Cara menggunakan mangkuk nasi dan sumpit.

(Sumber: Sandika, 2007: 163)

\section{b) Sumpit}

Pada awalnya sumpit terbuat dari batang bambu yang ujungnya saling berhubungan, kemudian pada masa $10 \mathrm{M}$ sumpit berkembang pemakaiannya menjadi dua batang yang terpisah. Jika diamati, ujung atas sumpit tradisional Cina berpenampang persegi empat dan ujung sebaliknya berbentuk bulat. Bulat adalah simbol Tuhan, sedangkan persegi empat adalah simbol manusia. Hal ini mengandung maksud bahwa ujung bawah sumpit (yang melambangkan Tuhan) tidak boleh bersentuhan dengan bibir (manusia), yang boleh bersentuhan adalah pangkal sumpit yang berpenampang persegi empat.

\section{c) Mangkuk mie}

Mangkuk ini berdiameter lebih besar daripada mangkuk nasi atau mangkuk sup. Selain untuk mie, mangkuk ini juga dapat digunakan untuk wadah sayuran dan lauk pauk di atas meja.

\section{d) Piring saji}

Terdapat dua jenis piring saji, yakni: piring saji oval dan piring saji bulat. Penggunaan kedua jenis piring ini bergantung pada bentuk dan porsi sajian. Misalnya untuk penyajian ikan dan mie biasanya digunakan piring saji oval.

\section{e) Cawan minum}

Cawan minum ini dilengkapi dengan tutup cangkir yang befungsi sebagai pelindung dan juga untuk membersihkan pinggiran cawan dari sisa tetesan seusai minum (lihat gambar 4). Pada saat minum tutup cawan tidak boleh dilepaskan dari badan cangkir demi menjaga kesopanan. 


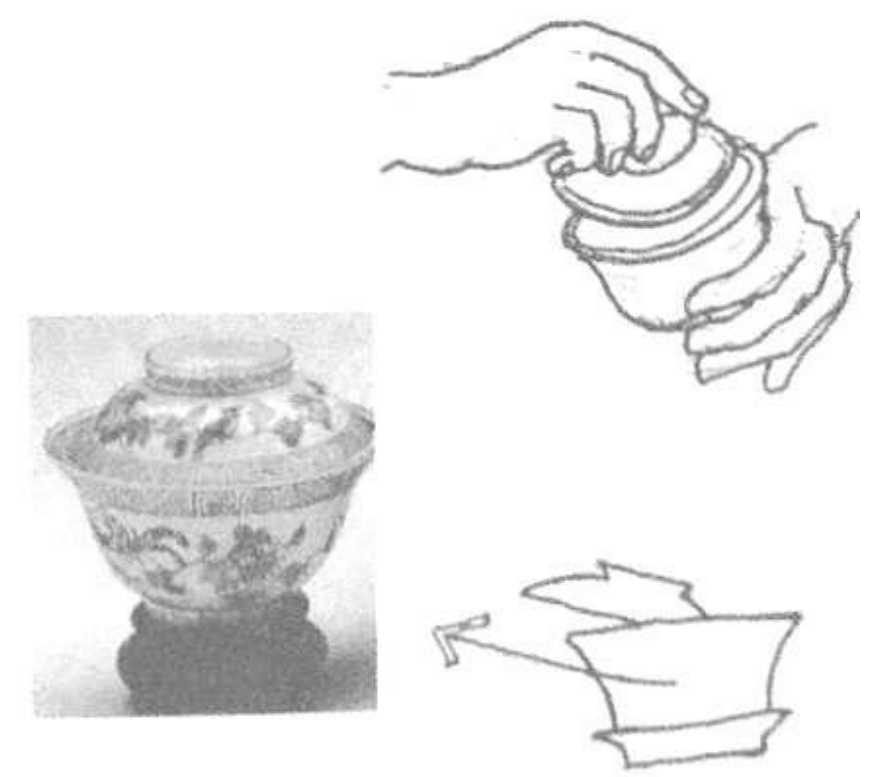

Gambar 4. Cawan minum dan cara penggunaannya (Sumber: Sandika, 2007: 163)

\section{f) Sendok Bebek}

Bentuk dari sendok bebek dibuat sedemikian rupa sehingga ketika sendok diangkat, sisi bawahnya yang bisa menetes kuah dapat digesekan di pinggiran mangkuk agar kuah tidak menetes. Di samping itu, sisi bawah yang mendatar juga memudahkan peletakan sendok di atas meja (lihat gambar 5).

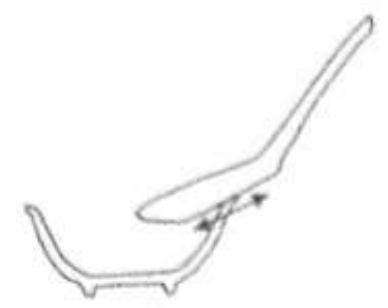

A

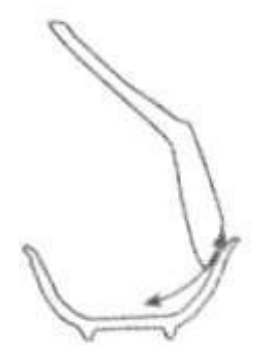

C

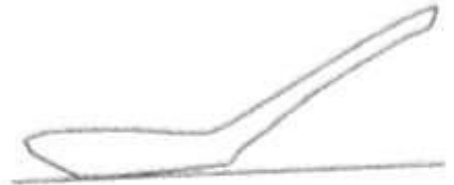

B

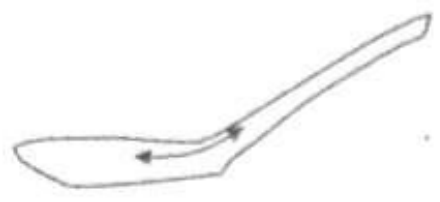

D

Gambar 5. Sendok bebek dan cara penggunaannya (Sumber: Sandika, 2007: 164)

Masakan Cina peranakan adalah hidangan percampuran berbagai macam budaya tetapi juga memiliki identitasnya tersendiri, terlihat jelas dalam masakan peranakan 
sampai sekarang. Mungkin ini merupakan jenis perpaduan masakan yang sesungguhnya-masakan pedas Melayu, Indonesia, Thai dan percampuran bumbubumbu Eropa dengan cara memasak ala Chinese. Kue-kue yang lezat juga tidak lepas daripada hidangan Nyonya. Pada mulanya, leluhur kaum Cina peranakan yang datang dari Tiongkok (sinkheh) mungkin mencoba makanan setempat namun tidak cocok dengan selera mereka. Untuk memasak makanan seperti di tempat asal mereka, bahannya tidak selalu ada, hasilnya mereka mencoba membuat masakan yang sesuai dengan selera mereka dengan bahan-bahan setempat. Akibatnya, muncul jenis-jenis makanan baru yang berbeda dan anak-anak mereka cenderung menyukai masakan ibunya (nyai) yang lebih menyukai masakan lokal, namun tetap dipengaruhi oleh selera sang ayah (Helen Iswara dalam Kwa dkk., 2009). Dalam waktu senggangnya, Nyonya menghabiskan waktunya di dapur mempersiapkan masakan-masakan yang lezat, mereka menyambut suaminya - Baba yang bepergian ke luar negeri untuk urusan bisnis dalam jangka waktu yang lama-dengan hidangan-hidangan yang mengugah selera (Suan, 2004: 14).

Kaum Cina peranakan adalah orang yang rewel dalam masakan-sangat kritikal terhadap makanan yang serampangan, berhati-hati dalam pemilihan warna masakan dan kue-kuenya untuk menyesuaikan dengan keadaan yang gembira atau sedih. Mereka sangat pemilih dengan hidangan untuk kombinasi makanan yang sesuai untuk dihidangkan di atas meja. Untuk hari biasa, Nyonya menyediakan sarapan yang bergizi, seperti: bubur, mee suah, roti atau telur setengah matang. Hidangan makan siangnya sederhana namun seimbang yang terdiri dari nasi (makan pokok), dan tiga atau empat lauk pauk termasuk sup dengan kombinasi yang sesuai. Makanan biasanya diletakkan di dalam rantang warna-warni dan dihantarkan ke tempat kerja Baba. Untuk cemilan, Nyonya biasa menghidangkan makanan yang pedas. Makan malam dihidangkan lebih mewah karena seluruh anggota keluarga pulang dari kantor atau sekolah untuk menikmati hidangan rumah. Zaman dahulu, kaum Cina peranakan yang kaya memiliki banyak juru masak (bedinde) yang handal. Juru masak ini besar di lingkungan dapur Nyonya sehingga mereka sangat terampil untuk menumbuk bumbu, menggoreng rempah, memanggang, hingga teknik memotong sayuran dengan bentuk dan ukuran yang berbeda untuk resep yang berbeda. Ada pula keluarga peranakan yang mempekerjakan koki Hainan untuk menjadi pengawas atas dapur mereka.

\section{Jenis Makanan}

Kaum peranakan di Malaysia dan Singapura sangat menggemari masakan kuah kuning kental dengan rempah dan santan yang mereka sebut curry. Di Indonesia, masakan ini lebih dikenal dengan sebutan opor. Ada berbagai jenis opor di seluruh Indonesia, Nyonya yang ada di setiap tempat memasak opor dengan ciri khas daerahnya masingmasing. Ayam buah keluak adalah makanan yang sangat populer bagi kaum peranakan di Malaysia dan Singapore. Bahkan perwakilan dari Chilli Padi Nonya Restaurant, Patricia Lee, ketika diwawancarai berpendapat bahwa masakan ayam buah keluak adalah masakan yang paling dapat mewakilkan masakan peranakan di Singapura, mereka berpendapat ketulenan restoran peranakan dinilai dari bagaimana mereka menghidangkan ayam buah keluaknya (Suan, 2004: 68). Di Indonesia, ayam buah 
keluak cukup dikenal di Jawa Barat walaupun resepnya agak berbeda dengan ayam buah keluak yang ada di Singapura dan Malaysia.

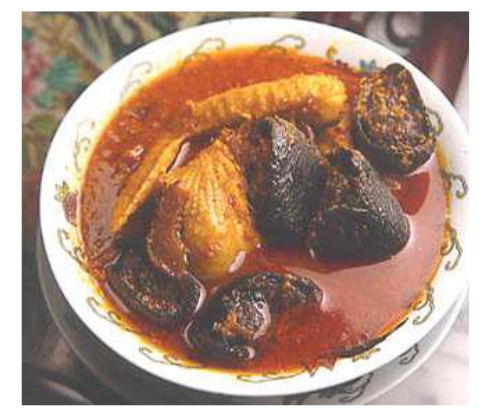

Gambar 6. Ayam buah keluak Singapura

(Sumber: http://www.makansutra.com/Makanzine/Nov99/ayambk/photo1.html)

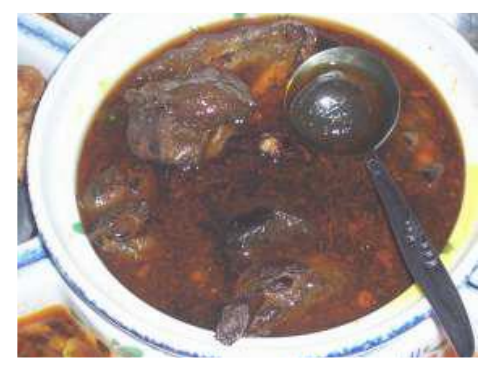

Gambar 7. Ayam keluak Indonesia

(Sumber: http://chl-mettakarunamudita.blogspot.com/2009_01_25_archive.html)

Lunpia atau lumpia sangat bervariasi di Indonesia. Lumpia padang juga disebut popia, isinya dibuat dari irisan bengkoang, diberi udang, daging, tahu, telur, sedikit kecap asin dan sedikit kecap manis. Kulit pembungkusnya dilapisi dengan daun selada dan diulasi cabai giling (lihat gambar 8).

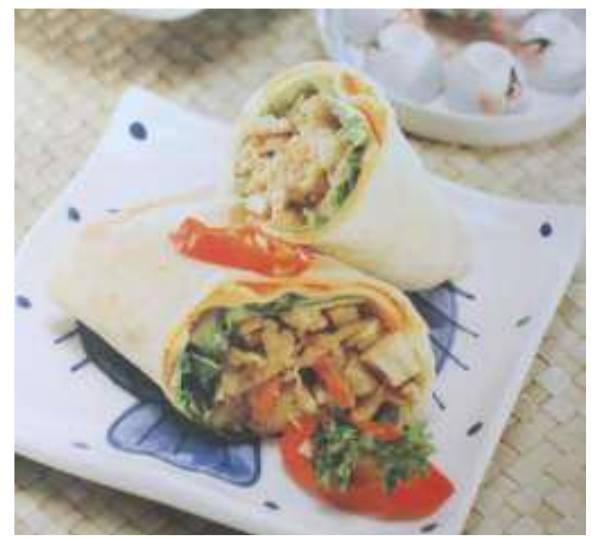

Gambar 8. Lumpia padang

(Sumber: Kwa dkk., 2009: 229)

Lumpia ini mirip dengan poh piah yang ada di Singapura dan Malaysia. Di Jakarta, Lumpia dimakan dengan sambal kacang asam manis. Kaum peranakan di Semarang tidak menggunakan bengkoang sebagai isi lumpia, mereka menggantikanya dengan rebung yang berbau khas. Lumpia semarang ada yang digoreng ada yang tidak. Lumpia 
juga dikenal di beberapa tempat lainnya dengan ciri khas yang berbeda (Kwa dkk., 2009: 227). Masih banyak jenis masakan peranakan yang ada di setiap daerah di seluruh Indonesia, Malaysia dan Singapura, semua jenis masakannya mungkin serupa, tetapi selalu memiliki identitas yang berbeda namun memiliki keotentikannya masingmasing.

\section{Kue}

Kue-kue untuk sesaji biasanya manis dan sering diberi warna merah. Konon warna merah mengundang keberuntungan. Warna putih hanya untuk berkabung, karena itu bakpao yang kulitnya putih diberi tutul merah (lihat gambar 9). Kue lapis juga digemari, ada lapis legit, kue pepe, kue lapis dari tepung beras, kue talam, dan lain-lain. Konon itu melambangkan rezeki yang bertumpuk-tumpuk. Kue kering yang populer di disediakan pada waktu Tahun Baru Imlek memperlihatkan pengaruh Belanda, yakni kue nastar, batang keju, kue semprit, dan sebagainya.

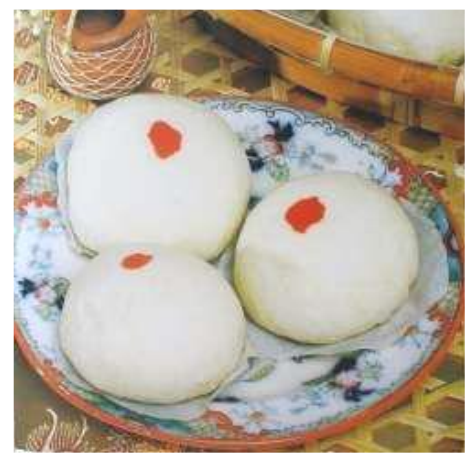

Gambar 9. Bakpao

(Sumber: Kwa dkk., 2009: 237)

Kue-kue yang berwarna-warni adalah kebanggaan seorang nyonya sebagai pembuatnya. Mereka menggunakan bahan pewarna alami sebagai bahan daripada kuenya. Nyonya menggunakan ekstrak angkak (annatto seeds) untuk warna merah, bunga telang (blue pea flower) untuk warna biru, daun pandan untuk warna hijau, kunyit untuk warna kuning, dan warna coklat diambil dari dari gula aren. Penggunaan warna pada kue tidak hanya digunakan untuk menarik perhatian, tetapi dalam cara tertentu warna pada kue tersebut mengandung arti tersirat ( Suan, 2004: 74).

\section{Dapur}

Kaum Cina peranakan percaya bahwa dapur merupakan perut rumah mereka, oleh itu dapur dianggap sangat penting oleh Baba sebagai pusat dari kehidupan dan kegiatan rumah tangga. Dalam masyarakat Chinese, kehidupan sosial dan religius diekspresikan melalui makanan, kaum ini menggunakan makanan sebagai persembahan untuk leluhur, menandakan sumpah, bahkan untuk menandakan musim dan festival (lihat Lee dan Chen, 1998). Dapur di rumah Baba biasanya terletak di belakang atau terpisah dengan bangunan rumah, hal ini memudahkan penyedia bahan makanan untuk menghantarkan bahan-bahan yang dipesan oleh Nyonya. Selain itu dapur yang terpisah juga menandakan sebagai tempat kekuasaan kaum wanita di rumah itu. 


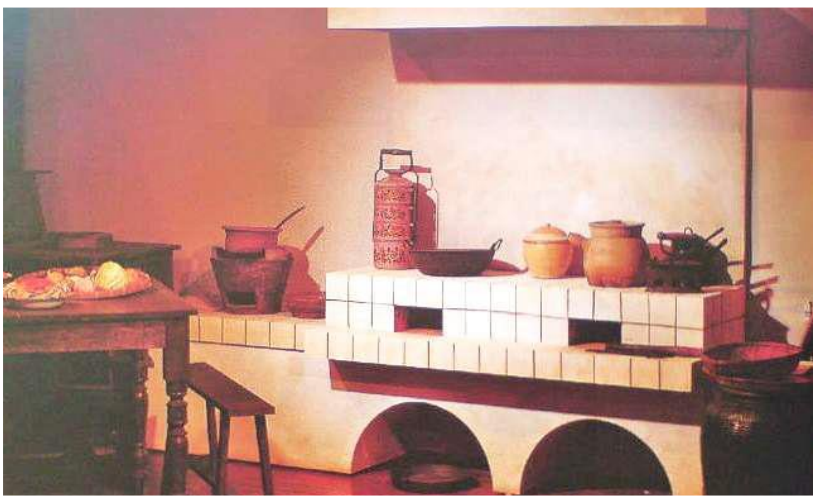

Gambar 10. Dapur Cina peranakan

(Sumber: Lee dan Chen, 1998: 106)

Tidak mengherankan jika dapur kaum Cina peranakan dianggap sebagai gudang dari rempah-rempah, bumbu masak dan bahan-bahan masak lainnya. Dapur ini tidak hanya lengkap akan bahan-bahan masakan cina (seperti: kecap soya, jahe, bawang dan lainnya) dan bahan-bahan lokal (seperti: terasi, asam, daun ketumbar, sereh, dan lainnya) tetapi juga dilengkapi oleh bahan-bahan makan impor dari Eropa yang sulit ditemukan pada zamannya.

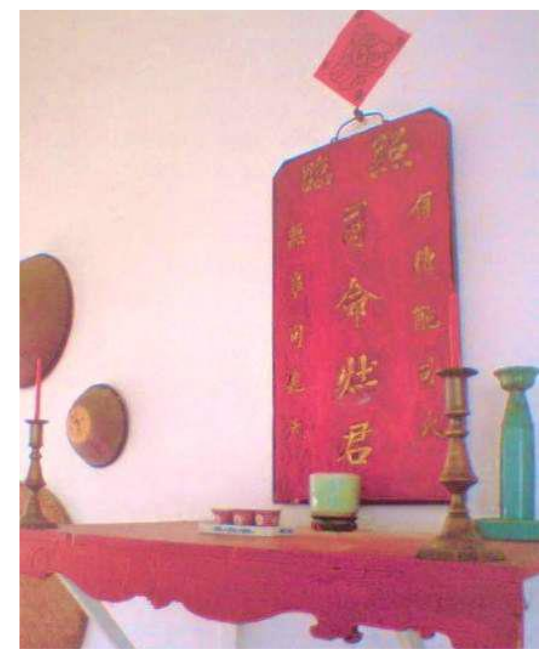

Gambar 11. Dewa dapur

(Sumber: Lee dan Chen, 1998)

Kaum Cina peranakan juga memuja dewa dapur (Datok Dapoh), altar dewa dapur biasa diletakkan di dekat tungku memasak. Altarnya tidak terbuat dari patung, melainkan kertas atau plakat merah dengan nama dewa tersebut (lihat gambar 11). Mereka percaya dewa dapur dikirim oleh kaisar langit. Sebelum Tahun Baru Imlek, kaum ini percaya bahwa dewa dapur akan naik ke langit untuk memberikan laporan kepada kaisar langit tentang kebaikan dan keburukan mereka, oleh karena itu nyonya akan mempersembahkan kue-kue manis dan minuman arak anggur agar dewa dapur melaporkan lebih banyak tentang hal-hal yang baik. 


\subsubsection{Level tengah (kebiasaan makan dan etiket)}

\section{Kebiasaan makan}

Kaum cina peranakan yang masih bisa berbahasa mandarin biasanya lebih sering memakan masakan ala cina dan masih menggunakan sumpit untuk makan. Ketika kaum peranakan bersosialisasi dengan orang-orang Eropa, mereka menggunakan garpu dan sendok untuk makan. Pada kesehariannya, Baba dan Nyonya makan seperti gaya Asia Tenggara-menu pembuka, menu utama, sup, sayur dan nasi dihidangkan secara bersamaan. Penyuguhan makanan yang lengkap menarik perhatian dan meningkatkan nafsu makan. Nyonya tidak menggunakan daun pisang untuk menjadi wadah makanannya sehari-hari, mereka menggunakan perangkat makan dari porselen yang berwarna-warni dengan perpaduan warna-warna yang cerah. Setiap rumah memiliki piring, mangkuk, cangkir, sendok, garpu, dan peralatan makan lain dengan berbagai jenis ukuran. Semuanya dipilih dan disesuaikan dengan waktu penggunaannya.

\section{Etiket makan}

Di keluarga besar, biasanya meja orang tua dan tamu dipisahkan dengan meja untuk anak-anak. Ketika ada jamuan makan, anak-anak diperbolehkan makan setelah orang tua dan tamunya selesai makan. Prinsip keseimbangan fan dan cai diterapkan dalam menghidangkan sebuah makanan. Fan dapat diartikan sebagai makanan pokok (umumnya nasi), sedangkan cai diartikan sebagai lauk pauk yang terdiri dari daging dan sayuran. Kombinasi fan dan cai ini dahulu disebut pei (pasangan)-sesuatu yang berpasangan namun keseimbangannya perlu dijaga (Yasmin, 1993: 10). Etiket ini ditekankan oleh Konfusius agar manusia dapat menahan diri terhadap makanan. Etiket makan juga mencakup posisi duduk anggota keluarga di meja makan. Faktor utama dalam posisi penempatan adalah jenis kelamin anggota keluarga dimana posisi air (yin) ditempati oleh laki-laki dan api (yang) ditempati oleh perempuan sehingga selaras dengan prinsip ajaran Tao. Selain itu arah selatan juga merupakan arah yang paling dihormati sehingga orang yang makan arah selatan utamanya adalah laki-laki.

Menurut Tan dan Fee (2004), kaum cina peranakan yang sudah tua biasanya suka makan dengan menggunakan tangan seperti orang Melayu dan India. Dalam aturan yang benar, mereka harus mencuci tangan sebelum makan, dan harus menggunakan tangan kanan untuk makan, hal ini juga diharuskan kepada orang yang bertangan kidal, karena penggunaan tangan kiri tidak sopan-tangan kiri digunakan untuk membersihkan bokong setelah buang air besar.

\subsubsection{Level dalam (makna simbolik budaya makan)}

Dalam masyarakat Cina, makan memegang peranan yang penting, karena makan dipandang sebagai pemersatu keluarga, dan juga kesatuan clan (struktur sosial) yang mempengaruhi kesatuan ekonomi keluarga. Di meja makan, sikap penghormatan anak kepada orang tua juga diterapkan dimana seorang anak yang berbakti hendaklah menghantarkan makanan kepada orang tuanya sebelum anak itu mendapatkan makanannya, bakti ini tidak hanya ditujukan kepada orang tua, tetapi juga arwah nenek moyangnya. Baik dari segi sosial dan religi, makanan memiliki fungsi yang sama 
yakni sarana menjaga hubungan baik masyarakat (seperti: kerabat, relasi bisnis, dsb.), sedangkan dari segi religi, makanan adalah sarana untuk menjaga hubungan baik dengan arwah leluhur dan dewa-dewa (Yasmin, 1993: 16).

Penganut Konfusius sangat menghargai seni memasak, sehingga banyak menetapkan standar makanan dan etiket makan. Konfusius berpendapat bahwa masakan yang benar bergantung pada upaya percampuran bermacam-macam rasa dan bumbu. Masing-masing bumbu tidak dapat berdiri sendiri, melainkan menjadi satu kesatuan yang harmonis, dan rasa makanan adalah hasil dari suatu keharmonisan.

Jenis makanan yang dihidangkan dipengaruhi oleh kondisi, situasi, kelas sosial, pekerjaan, dan jenis kelamin. Dalam jamuan tertentu, jenis hidangan menunjukkan penghargaan kepada sang tamu. Konsep makanan adalah sesuatu yang dihasilkan melalui usaha bersama yang kemudian disatukan dalam olahan di dapur yang sama. Keluarga dalam masyarakat cina diumpamakan sebagai peralatan masak berupa tungku sehingga keluarga diartikan sebagai lingkungan kebersamaan yang mengelola makanan dalam satu tungku (Wolf, Arthur P. and Chieh-shan Huang, 1980: 58).

Ajaran Tao menekankan kebersihan dan segi pengolahan makanan, karena makanan dimakan oleh tubuh dan menghasilkan umur panjang. Ajaran Tao juga menekankan seni kesehatan untuk umur panjang. Ajaran ini menerapkan prinsip keseimbangan yin dan yang, keselarasannya menghasilkan kehidupan yang baik.

\section{KESIMPULAN}

Berdasarkan dari paparan di atas didapat kesimpulan sebagai berikut;

a. Budaya Cina peranakan dipengaruhi oleh banyak budaya-budaya di sekitarnya, terutama budaya Cina, Eropa dan budaya setempat (Melayu, Jawa, Bali, dan lainnya) Hal ini dapat dilihat dari kebiasaan mereka sehari-hari yang sudah terbaur.

b. Budaya Cina peranakan harus dilihat sebagai sebuah transformasi budaya yang dinamis tapi dalam konteks budaya makan, budaya Cina masih dominan.

c. Baba dan Nyonya adalah kaum pertama yang akrab dengan budaya global. Mereka adalah kaum yang benar-benar multikultural dan menganggap dirinya orang yang terbuka dengan dunia luar, mereka sering bepergian dan dididik dengan budaya yang berbeda-beda, dan mereka cukup percaya diri akan keunikan mereka masing-masing.

d. Semakin kaya dan terpandangnya sebuah keluarga Cina peranakan, semakin mereka terpengaruh oleh budaya-budaya barat yang mewah. Bahkan beberapa dari mereka melupakan budaya asli mereka dan hidup dengan gaya Eropa.

e. Kaum Cina peranakan memang dianggap kaum yang sangat mudah untuk beradaptasi dengan budaya dan lingkungan di sekitarnya, namun mereka juga dianggap sebagai kaum yang tidak memiliki jati diri, di lain pihak mereka justru mengganggap bahwa itulah jati diri mereka, yakni kaum multikultural dengan identitasnya yang unik. 
f. Dari segi kuliner, Nyonya dan para bedinde dinilai sebagai orang yang handal dan kritikal tentang seni memasak. Mereka tidak pernah berhenti untuk menemukan resep-resep baru yang inovatif dan lezat.

g. Kaum ini juga menyukai benda-benda yang bewarna-warni. Namun mereka juga sangat selektif dalam pemilihan warna dan sangat ahli dalam penyesuaian warna-warna (dari busana hingga ke makanan) yang disesuaikan dengan waktu dan acaranya (baik gembira maupun berkabung).

h. Mereka juga masih mempertahankan beberapa ajaran Konfusius, terutama dalam hal berbakti kepada orang tua-sering sekali dipraktikan dalam pemujaan leluhur yang sangat berlebihan.

i. Cara makan Cina peranakan sangat beragam tergantung jenis makanan yang dihidangkan, mereka dapat makan dangan tangan, sumpit, garpu dan sendok tergantung acara dan tempat mereka makan.

j. Depskripsi budaya Cina peranakan sesungguhnya menunjukkan bahwa kaum ini telah turut berpartisipasi dalam kebinekaan masyarakat Indonesia. Mereka merasa telah menjadi bagian yang tak terpisahkan dari masyarakat Indonesia, bukan sebagai orang asing di negeri yang asing.

\section{DAFTAR PUSTAKA}

Ham, Ong Hok. 2005. Riwayat Tionghoa Peranakan di Jawa. Depok: Komunitas Bambu.

Kwa, David, dkk. 2009. Peranakan Tionghoa, Sebuah Perjalanan Budaya. Jakarta: Intisari dan Komunitas - Lintas Budaya Indonesia.

Kwartanada, D., \& Noor, M. M. 2006. Lahirnya Satu Generasi Baru Tionghoa Di Jawa: Pendidikan Dan Resinifikasi Anak-Anak Peranakan Di Yogyakarta 1930-An S/D 1950-An. S.I.: S.n.

Lee, Peter \& Chen, Jennifer. 1998. Rumah Baba: Life in a Peranakan House. Singapore: National Heritage Board.

Lin, Rung Tai. 2007. Transforming Taiwan Aboriginal Cultural Features into Modern Product Design: A Case Study of a Cross-cultural Product Design Model, International Journal of Design Vol.1 No.2 2007

Sandika, Riska. 2007. "Budaya Makan Cina dan Desain Peralatan Makan Masyarakat Tionghoa Perkotaan", dalam Jurnal IImu Desain Fakultas Seni Rupa dan Desain ITB Bandung Vol. 2 No. 3 September 2007.

Suan, Tan Gek. 2004. Gateway to Peranakan Food Culture. Singapore: Asiapac Books.

Tan, G. S., \& Fee, W. 2004. Gateway to Peranakan food culture. Singapore: Asiapac.

Winarni, R. 2009. Cina pesisir: Jaringan bisnis orang-orang Cina di pesisir utara Jawa Timur sekitar abad XVIII. Denpasar, Bali: Pustaka Larasan.

Yasmin, Teresia. 1993. Makanan Cina dalam Kehidupan Sehari-hari dalam Upacara Tradisional Menurut Orang Cina di Jakarta, (Skripsi Sarjana). Jakarta: Fakultas Sastra, Universitas Indonesia. 